\title{
Pelatihan Menyusun Bahan Ajar Untuk Pengembangan Bahasa Arab Di Ponpes Al Hikmah Karangmojo Gunungkidul
}

\author{
Ahmad Hidayatullah Zarkasyi ${ }^{1}$, Fitra Awalia Rahmawati ${ }^{2 *}$, Muhammad Wahyudi ${ }^{3}$, \\ Imroatul Istiqomah ${ }^{4}$ \\ ${ }^{1}$ Pascasarjana Universitas Darussalam Gontor, ${ }^{2,3}$ Program Studi Pendidikan Bahasa, Fakultas \\ Tarbiyah, Universitas Darussalam Gontor, ${ }^{4}$ Program Studi Aqidah dan Filsafat Islam, Fakultas \\ Ushuluddin \\ Universitas Darussalam Gontor \\ Email: fitraawaliarahmawati@unida.gontor.ac.id ${ }^{2 *}$
}

\begin{abstract}
Abstrak
Menyusun bahan ajar adalah salah proses penting dalam penyelenggaraan pendidikan dan pengajaran. Khususnya, pembelajaran bahasa asing menggunakan metode langsung (direct method). Bahan ajar yang tepat akan mempermudah pengajar dan peserta didik dalam menguasai dasar-dasar bahasa asing. Kegiatan Pengabdian kepada Masyarakat ini dilakukan dengan metode pelatihan dan pendampingan menyusun bahan ajar bahasa Arab berbasis mufradāt yawmiyah (kosakata harian) terhadap 6 guru penanggungjawab program bahasa di Ponpes Al Hikmah Karangmojo. Dilanjutkan dengan uji coba bahan ajar kepada 42 calon pengajar bahasa dari pengurus organisasi santri. Penelitian ini menghasilkan, bahwa dalam proses penyusunan bahan ajar, perlu memetakan sarana penunjang. Di antaranya adalah 1) indeks percakapan yang sering digunakan di pondok. 2) pemetaan kompetensi santri dalam berbahasa. 3) pembuatan materi secara berjenjang; dari sederhana hingga cukup.
\end{abstract}

Kata kunci: Metode Langsung; Bahan Ajar; Desain Pembelajaran; Pembelajaran Bahasa Arab

\begin{abstract}
Compiling teaching materials is one of the important processes in the implementation of education and teaching. In particular, foreign language learning uses the direct method. The right teaching materials will make it easier for teachers and students to master the basics of foreign languages. This Community Service activity was carried out by means of training and mentoring in compiling Arabic language teaching materials based on mufradāt yawmiyah (daily vocabulary) for 6 teachers in charge of the language program at Al Hikmah Ponpes Karangmojo. Followed by the trial of teaching materials to 42 prospective language teachers from the board of the santri organization. This research results that in the process of preparing teaching materials, it is necessary to map the supporting facilities. Among these are 1) indexing the conversations that are often used in the boarding school. 2) mapping the competence of students in language. 3) designing materials for every stages; from beginner to expert.
\end{abstract}

Keywords: Direct Method, Teaching Material, Learning Design, Arabic Teaching

\section{PENDAHULUAN}

\author{
Pembelajaran bahasa Arab dengan \\ metode langsung telah menunjukkan \\ berbagai kemudahan tertentu. Di antaranya, \\ para peserta didik dapat secara langsung \\ mempraktekkan penguasaan bahasa mereka \\ tanpa terbebani hafalan-hafalan tentang \\ kaidah bahasa Arab. Metode ini, memang \\ bertujuan untuk mempercepat santri belajar
}

melalui praktek (learning by doing).

Bukan berarti tanpa kekurangan, karena metode ini membutuhkan kompetensi guru yang dapat memaksimalkan potensi santri untuk berkembang; yang dimulai dari penguasaan guru yang bersangkutan akan materi yang akan diajarkannya. Sehingga, dalam skema belajar bahasa melalui metode langung, bahan ajar menduduki peran yang 
cukup strategis, selain guru itu sendiri.(Rahmawati, Nur, \& Taqiyuddin, 2021; Zaid, 2012)

Ponpes Al Hikmah Karangmojo telah berdiri sejak 1989 terletak di Desa Sumberjo Kecamatan Karangmojo Kabupaten Gunungkidul Yogyakarta. Dimulai berdirinya, berawal dari keberadaan beberapa pengajian agama yang diinisiasi oleh $\mathrm{H}$. Jumakir dan H. Ngadeni al Huda (alm). Di masjid desa, yang berisi tentang materi keislaman praktis untuk keseharian. Kala itu, di tahun 1989-1990 tercetus ide pendirian pondok. Agar sistem pendidikan lebih bisa menyeluruh dan fokus. Tanpa meniadakan pengajian di masyarakat.(Taqiyuddin \& Rahmawati, 2020)

Pada perkembangannya, pondok tersebut lambat laun memiliki sekolah formal. Yang pada mulanya berdiri adalah Madrasah Aliyah (MA). Barulah disusul dengan SMP dan SMK. Kesemua muridnya adalah santri yang mukim di pondok. Yang paling menarik, bahwa pondok ini menggratiskan biaya asrama dan uang makan seluruh santrinya.(Taqiyuddin \& Rahmawati, 2020) Sebagai salah satu pondok pesantren yang fokus pada pendidikan Islam, KH Harun Al Rosyid selaku pimpinan telah mencanangkan 10 kompetensi. Salah satunya adalah menguasai bahasa Arab dan Inggris.

Program ini mengintegrasikan materi

bahasa Arab ke dalam kurikulum pondok yang diajarkan setiap malam hari. Kegiatannya disebut Ma'had Ta'dib Islamiy (MTI) yang pengelolaannya dilimpahkan kepada ust Hanung Hizbullah Hamda, S.H., M.Pd.I yang juga kepala sekolah di Madrasah Aliyah.(Karmila, 2020)

Beberapa materi yang terkait dengan bahasa Arab seperti Muthālaah, Muhādatsah, dan Durüsul Lughah. Kesemuanya telah menggunakan beberapa buku terbitan Gontor, seperti Buku Muhādatsah Yawmiyah dan Durūs al-Lughah alArabiyah.(Hafidzuddin, 2020)

Yang menjadi kendala, bahwa beberapa kosakata dan setting dalam buku ajar tersebut, masihlah menggambarkan suasana Gontor. Sedangkan para santri mayoritas tidak pernah mengetahui secara fisik hal-hal yang ada di Gontor. Sehingga, beberapa pelajaran kurang dapat dikuasai secara maksimal.(Bakri, 2017; Budi \& Apud, 2019)

Latar belakang inilah yang mendasari urgensi penyusunan bahan ajar yang lebih merepresentasikan setting sosial dan budaya di pesantren $\mathrm{Al}$ Hikmah berikut pula kegiatan dan hal-hal fisik seperti infrastruktur pendidikan di lingkungan pondok yang selalu digunakan sebagai tempat kegiatan santri.

\section{METODE}

Kegiatan pengabdian ini dilaksanakan dalam bentuk pemberian pelatihan dan pendampingan. Satu sisi lain, mengandalkan potensi pesantren dalam memotivasi peserta didiknya. Sehingga, kegiatan ini tidak hanya mengandalkan pihak kampus saja; sehingga ditakutkan kegiatan bahasa menjadi tidak berkelanjutan. Justru, perlu melibatkan pesantren dalam beberapa hal-hal teknis, sebagai salah satu bentuk model pendidikan kepada santri untuk memanage institusi mereka sendiri melalui learning by doing.

Harapannya, dengan metode ini, pihak ponpes khususnya santri yang sudah menjadi pengurus dapat meningkatkan rasa tanggungjawab. Dimulai dari pembentukan rasa percaya diri dan optimis bahwa dirinya mampu mengajar adik kelas mereka. Sehingga, persiapan bahan ajar berikut pelatihannya menjadi penting dan perlu diutamakan.

Kegiatan yang sudah disusun, ditetapkan dalam sebuah target yang diberi timing. Sehingga, kegiatan pengabdian dapat terukur dan terstruktur, berikut memudahkan pengelola pesantren untuk melakukan evaluasi baik kelebihan maupun kekurangan dari kegiatan tersebut. Berikut ini adalah timing kegiatannya: 
Tabel 1. Timing kegiatan Penyusunan Bahan Ajar

Berdasarkan timing tersebut telah ditetapkan beberapa kegiatan primer, yakni: 1) pemetaan kompetensi, 2) penyusunan bahan ajar, 3) uji coba bahan ajar. Tiga hal tersebut setidaknya merupakan program inti dari pengabdian masyarakat ini.

\section{HASIL DAN PEMBAHASAN}

Berdasarkan metode yang telah ditetapkan; pelaksanaan kegiatan pengabdian dapat dirumuskan secara teknis. Dalam awal mula merancang bahan ajar, tim dosen berkonsultasi dan berkomunikasi dengan pihak pesantren dalam rangka mendapatkan data-data kompetensi santri. Untuk dijadikan baseline dalam menentukan garis besar materi yang akan ditetapkan untuk disusun.

Dari hasil konsultasi dengan pengelola pesantren, berikut guru di Madrasah; ditemukan bahwa kompetensi yang perlu didukung adalah seputar kompetensi dasar mengenai kosakata seharihari. Hal ini dipetakan dari beberapa wawancara terstruktur dan survey kepada santri; baik uji petik secara spontan maupun terjadwal.

Selain itu, ditemukan pula bahwa nilai bahasa Arab selama tahun sebelumnya; menegaskan kesimpulan di atas. Bahwa materi bahasa Arab di Buku Ajar Madrasah, lebih bersifat kognitif. Yakni materinya mengandung gambar dan alat peraga yang kebanyakan belum pernah disaksikan oleh santri. Seperti Monas, masjid istiqlal, dan lainnya. Dan meski gurunya dapat menjelaskannya dengan bantuan video, kemampuan psikomotorik santri dalam mengenali kata kerja dan kata benda yang ada di sekitar pesantren tidak bisa dikatakan meningkat dengan signifikan.(Rahmawati, 2020)

Selain itu, dari segi nilai soal yang mengandung aspek psikomotorik di kelas,

\begin{tabular}{|c|c|c|c|}
\hline No & Waktu & Kegiatan & \\
\hline 1 & November & Pemetaan kompetensi santri & \\
\hline 2 & November (akhir) & Awal Penyusunan Bahan ajar & \\
\hline 3 & November (akhir) & Pembukaan Resmi Program & \\
\hline 4 & Desember (awal) & $\begin{array}{l}\text { Masa Pendampingan dan } \\
\text { mengajar }\end{array}$ & Persiapan \\
\hline 5 & $\begin{array}{l}\text { Desember } \\
\text { (tengah) }\end{array}$ & Uji Coba Bahan Ajar & \\
\hline 6 & Desember (akhir) & Evaluasi dan Perbaikan & \\
\hline 7 & Januari (awal) & Sosialisasi dan Penggunaan & \\
\hline
\end{tabular}

dihasilkan hipotesis bahwa pernyataan guru bahasa Arab cukup sesuai dengan fakta lapangan:

Tabel 2. Nilai rata-rata soal jenis psikomotorik bahasa Arab madrasah.

\begin{tabular}{ccc}
\hline No & Tahun & Rata-rata \\
\hline 1 & 2018 Genap & 76,798 \\
2 & 2019 Ganjil & 77,107 \\
3 & 2019 Genap & 76,203 \\
4 & 2020 Ganjil & 77,745 \\
5 & 2020 Genap & 77,057 \\
& Rata-rata Umum: & $\mathbf{7 6 , 9 6 2}$
\end{tabular}

Dari data di atas, dapat terbaca bahwa nilai rata-rata masih berhimpitan dengan KKM mata pelajaran, yakni 76 . Sehingga, dapat raport rata-rata dituliskan sebagai: "masih perlu belajar lebih keras untuk...."

Kesimpulan lain yang didapat, yakni dari direktur penyelenggara kurikulum pesantren. Bahwa kebanyakan santri, karena tidak tahu lantas menjadi malu bertanya. Padahal, saat ada KKN; dan dibuat berbagai papan kosa kata, para santri dapat terpacu dalam mengusahakan menggunakan bahasa yang baku dan baik. Mungkin saja, para santri perlu difasilitasi materi ajar yang sesuai dengan kebutuhan mereka sehari-hari dahulu. Untuk materi yang lebih rumit, bisa disusun lain waktu jika kompetensi mereka sudah meningkat sesuai harapan.(Hafidzuddin, 2020)

Tahap selanjutnya, adalah survey dari sampel. Yang pada kali ini, adalah santri aktif di pesantren. Berdasarkan data yang diambil seizing pengelola pesantren, pada tahun ajaran kali ini, jumlah santri dapat 
dilihat pada tabel berikut ini:

Tabel 3. Jumlah santri Pesantren al Hikmah.

\begin{tabular}{cll}
\hline No & Tahun & Rata-rata \\
\hline 1 & Santri & 150 \\
2 & Santriwati & 209 \\
& Jumlah Total: & $\mathbf{3 5 9}$
\end{tabular}

Dari jumlah tersebut, diambil sampel sekitar 20\%, yakni 80 orang. Data tidak diambil langsung, melainkan melalui wawancara kepada dewan asatidz yang turun langsung membantu pendidikan dan pengajaran di pesantren, di bawah koordinasi direktur. Data yang ingin diketahui oleh tim dosen, yakni seputar baseline tentang kosakata atau ungkapan yang sering digunakan santri.

Gambar 1. Kegiatan Pemetaan kompetensi santri

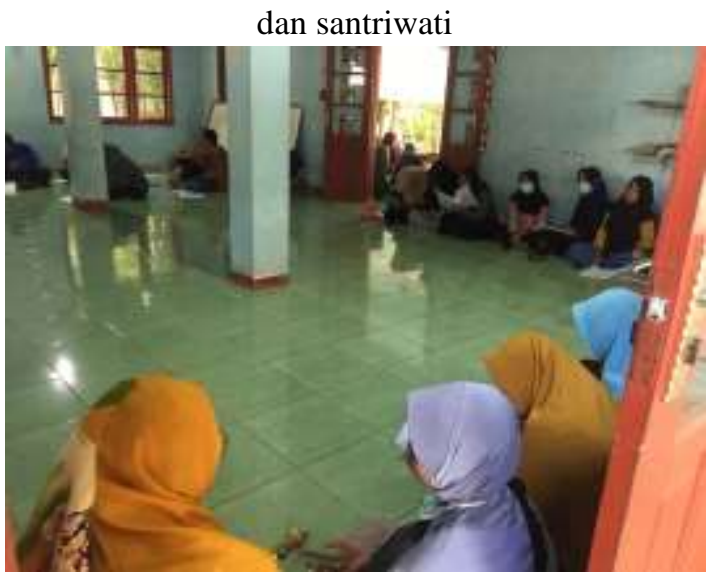

Dari mereka, dikonfirmasi secara hipotesis bahwa mayoritas santri membutuhkan tambahan fasilitas berupa akses kepada literasi berbasis kosakata berbahasa Arab. Selain juga, ada aspek teknis dari segi disiplin. Namun, program tersebut lebih pada internal pesantren. Sedangkan tim dosen fokus pada materi ajar saja. (Rahmawati \& Hafidzuddin, 2020)

Gambar 2. Rapat perumusan pelatihan

Dari pengambilan data tersebut, ditetapkan bahwa struktur bahan ajar yang dirancang untuk dibuat, adalah berbasis kosakata sehari-hari. Yang dibagi menjadi tiga tingkat: dasar, menengah, dan tinggi. Dari segi kosakata, dibagilah beberapa zonasi di mana seringnya terjadi percakapan para santri. Selanjutnya, dewan asatidz merekomendasikan 6 guru bantu untuk diikutsertakan dalam pelatihan menyusun bahan ajar. Detailnya adalah sebagai berikut:

Tabel 4. Daftar nama guru yang didampingi untuk menyusun bahan ajar

\begin{tabular}{|c|c|c|}
\hline No & Tema & $\begin{array}{l}\text { Nama guru } \\
\text { bantu }\end{array}$ \\
\hline 1 & $\begin{array}{l}\text { Di Masjid (fiy al } \\
\text { Masjid) }\end{array}$ & M Rizal Azhar \\
\hline 2 & Di Kelas (fiy al Fashl) & Helmi Yasir \\
\hline 3 & $\begin{array}{l}\text { Di Asrama (fizy al } \\
\text { Maskan) }\end{array}$ & $\begin{array}{l}\text { Listiana Nur } \\
\text { Hanifah }\end{array}$ \\
\hline 4 & $\begin{array}{l}\text { Di Dapur (fiy al } \\
\text { Math'am) }\end{array}$ & Nur Rahmawati \\
\hline 5 & $\begin{array}{l}\text { Di Kamar Mandi (fíy al } \\
\text { Hammām) }\end{array}$ & Wuri Ramdani \\
\hline 6 & $\begin{array}{l}\text { Di Lapangan (fìy al } \\
\text { Maydān) }\end{array}$ & Meisya Febi \\
\hline
\end{tabular}

Dari daftar tersebut, memudahkan pelatihan dilaksanakan secara intensif. Yakni, mereka membuat indeks kosakata yang disusun dalam bentuk daftar kosakata bahasa Arab hingga percakapannya. Pada tingkat rendah, diperlukan literasi berupa kosakata sederhana. Pada tingkat menengah, kosakata harus dihafalkan dan dimengerti. Pada tingkat tinggi, santri dituntut untuk dapat menghafal suatu rangkaian idiom bahasa Arab. Ini tentu belum semuanya mampu.

Salah satu hasil yang diselesaikan dari ikutserta guru dalam pelatihan ini, dapat kita lihat sebagai berikut:

Tabel 5. Contoh Kosakata yang disusun; berjudul "di Masjid" (fiy al masjid)

\begin{tabular}{clcr}
\hline No & Kata Indonesia & Kata Arab & \\
\hline 1 & Masjid & & \\
2 & Mimbar & & \\
3 & Mukena & & السمبرة \\
4 & Sajadah & &
\end{tabular}


$5 \quad$ Al - Qur'an

6 Pembesar Suara

$7 \quad$ Lantai dua

8 Kubah

9 Shaf

10 Makmum

11 Do'a

12 Sholat
A : Apa yang kamu lakukan setelah sholat tahajjud ?

مهبر الصوت

طبقة الثاني

قو

الهوف

(أمبأموم

الإعاء

ملاك

B : Saya membaca Al - qur'an, dan berdo'a kepada Allah

A : Sampai jam berapa kamu di masjid ?

B : Sampai jam 2.00

A : Semalam kamu pergi kemana ?

B : Saya semalam pergi ke masjid

A : Apa yang kamu lakukan di masjid?

B : Saya sholat tahajjud
Daftar kosakata di atas adalah tingkat dasar; atau disebut tingkat pemula. Dalam sistem pembelajaran bahasa, kosakata perlu dihafalkan agar dapat diketahuai rangkaiannya pada suatu kalimat. Lantas, perlu digunakan berkali-kali agar terbiasa. Selanjutnya, adalah contoh tingkat tinggi dari segi bahan ajar:

Tabel 6. Contoh Kosakata yang disusun; berjudul "di Masjid" (fiy al masjid)

\begin{tabular}{|c|c|}
\hline No & Ungkapan dalam Bahasa Arab \\
\hline 1 & ج : أُيْنَ ذَهَبْتِ الْبَارِحَةِ ؟ \\
\hline 2 & 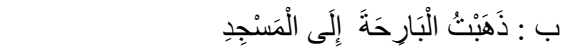 \\
\hline 3 & ج : مَاذَا تَعَعَلْينِنَ فِي الَْسَنْجِدِ ؟ \\
\hline 4 & 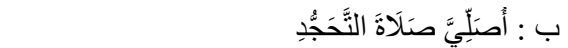 \\
\hline 5 & 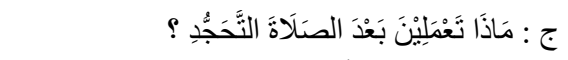 \\
\hline 6 & 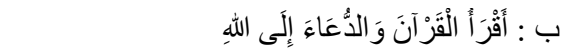 \\
\hline 7 & ج : حَنَّى أَبيُ سَاعَةِة فِي الْمَسْجِدِ ؟ \\
\hline 8 & ب : حَنَّى السَّاعَةِة الثَّانِيَةِ. \\
\hline 9 & ج : أَيْنَ ذَهَبْتِ الْبَارِحَةِ ؟ \\
\hline 10 & ب : ذَهَبْتُ الْبَارِحَةَ إِلَى الَْسَنْجِدِ \\
\hline 11 & ج : مَاذَا تَعَمَلِينَنَ فِي الَْسَنْجِدِ ؟ \\
\hline 12 & 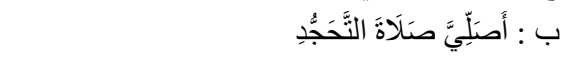 \\
\hline
\end{tabular}

Berikut disertakan terjemahan dalam bahasa Indonesianya. Agar dapat dikembangkan sendiri oleh santri pada nantinya.

Tabel 7. Contoh Kosakata yang disusun; berjudul "di Masjid" (fiy al masjid)

\section{SIMPULAN}

Sebagai suatu kegiatan pengabdian yang amat terbatas karena Covid-19, bahwa Darma perguruan tinggi tetap dapat dilakukan. Di antaranya, menyasar pesantren yang telah masuk kelas secara kalender akademik. Kegiatan pembelajaran bahasa Arab ini, dapat ditingkatkan dengan kolaborasi melalui pengabdian masyarakat dari kampus. Berupa pelatihan menyusun materi. Penyusunan bahan ajar, harus melalui tahapan-tahapan yang berdasarkan pada baseline pesantren itu sendiri. Sedangkan dari segi teknis, kegiatan pengabdian ini cukup layak dinilai sukses, Karena menerapkan model pembelajaran metode langsung; secara teoritis dapat menyumbang pemahaman mendasar tentang bahasa Arab.

\section{DAFTAR PUSTAKA}

Bakri, Muhammad Ali. 2017. "Metode Langsung (Direct Method) Dalam Pengajaran Bahasa Arab." Al-Maraji' Jurnal Pendidikan Bahasa Arab 1 (1): $1-24$.

Budi, Abdul Mufid Setia, and Apud Apud. 2019. "Peran Kurikulum Kulliyatul Mu'allimin Al-Islamiyah (Kmi) Gontor 9 Dan Disiplin Pondok Dalam Menumbuhkembangkan Karakter Santri." Tarbawi: Jurnal Keilmuan Manajemen Pendidikan 5 (01): 1-10.

Hafidzuddin, Sholeh. 2020. "Ringkasan Transkrip Wawancara Dengan Direktur Penyelenggaraan Kurikulum Pesantren (Hanung Hisbullah Hamda, S.H., M.Pd)."

Karmila, Karmila. 2020. "Manajemen Kurikulum Pada Sekolah Berbasis 
Pesantren Di SMP Al-Hikmah

Karangmojo." In Seminar Nasional

Pendidikan. Vol. 1.

Rahmawati, Fitra Awalia. 2020. "Ringkasan

Transkrip Wawancara Dengan Guru

Bahasa Arab MA (Muhammad

Taqiyuddin, $\quad$ S.H.I., $\quad$ M.Ag)."

Karangmojo Gunungkidul.

Rahmawati, Fitra Awalia, and Sholeh

Hafidzuddin. 2020. "Notulasi

Koordinasi Bersama Dewan Asatidz

Pesantren Terkait Program Bahasa."

Taqiyuddin, Muhammad, and Fitra Awalia

Rahmawati. 2020. "Profil Pondok

Pesantren Al Hikmah Karangmojo

Gunungkidul 2020.” Zenodo.

https://doi.org/10.5281/zenodo.3861859

Zaid, Abdul Hafidz. 2012. "Pendekatan Komunikatif Dalam Pembelajaran Bahasa Arab (Pengalaman Pondok Modern Darussalam Gontor)." AtTa'dib. 